\title{
A EDUCAÇÃO NO PERÍODO DA DITADURA MILITAR: O ENSINO TÉCNICO PROFISSIONALIZANTE E SUAS CONTRADIÇÕES $(1964-1985)^{1}$
}

\author{
Nara Lidiana Silva Dias Carlos ${ }^{2}$ \\ llane Ferreira Cavalcante ${ }^{3}$ \\ Olívia Morais de Medeiros Neta ${ }^{4}$
}

\section{Resumo}

Este trabalho é um estudo de revisão bibliográfica e documental sobre as mudanças educacionais ocorridas durante o período da ditadura civil militar (1964 - 1985). A análise documental se debruça sobre a Lei no 5.540, de 28/11/1968, que normatizou o ensino superior nacional e a Lei no 5.692 de 11/08/1971, que fixa diretrizes e bases para o ensino de $2^{\circ}$, tornando profissional toda a educação pública desse nível. Observa-se que as reformas do ensino superior e médio se entrelaçaram e foram feitas, em especial a segunda, em razão da primeira.

Palavras-chave: Ensino de $2^{\circ}$ grau; História da Educação; Educação Profissional.

\begin{abstract}
This paper is a bibliographical study and a documental analysis about the educational changes occurred during de military dictatorship in Brazil (1964-1985). The historical scenery and the documental analysis approaches the Law no 5.540, from November 28, 1968; that established new rules to graduation and the Law 5.692, from August, 11, 1971, that dictates the basis to a new second degree teaching in the period. It observes that the changes in graduation and in second degree teachings were connected and influenced one another, mostly, the second degree was a consequence of the first one.
\end{abstract}

Keywords: Second degree teaching; History of Education; Professional Education.

\section{Introdução}

No contexto do golpe civil militar de 1964 a educação brasileira passou por grandes modificações. Algumas dessas mudanças ocorreram por causa da pressão social, por meio dos movimentos sociais da década de 1960, como é o

\footnotetext{
${ }^{1}$ DOI: https://doi.org/10.22409/tn.16i30.p10088

${ }^{2}$ Historiadora, Mestre em Educação pelo Instituto Federal de Educação, Ciência e Tecnologia do Rio Grande do Norte. E-mail: <naralid@yahoo.com.br>

${ }^{3}$ Licenciada em Letras, Doutora em Educação, Docente do Instituto Federal de Educação, Ciência e Tecnologia do Rio Grande do Norte. E-mail: <ilanecfc@gmail.com>

${ }^{4}$ Historiadora, Doutora em Educação, Docente da Universidade Federal do Rio Grande do Norte. E-mail: <olivianeta@gmail.com>
} 
caso da reforma do ensino superior. Já outras alterações aconteceram por meio de imposição política, a exemplo da implantação da Lei ํㅜ 5.692/71, tornando a educação profissional universal e compulsória. Essa lei foi sancionada sem consulta pública e modificou todo o ensino básico brasileiro.

Antes de qualquer coisa, não devemos perder de vista a aliança feita entre o Estado Brasileiro e o capital estrangeiro. As alterações ocorridas no cenário educacional foram, em grande medida, para alimentar o capital e suprir as demandas do mercado. O Brasil estava inserido em uma conjuntura mundial, ditada pelo capital estrangeiro, numa busca desenfreada para legitimar o capitalismo e as ações do mercado, que passava pela conhecida crise de 1970, a denominada crise estrutural do capital.

Segundo Antunes (2009), foi a partir de 1970, após um grande período de acúmulo de capital, que o capitalismo passou a sinalizar um quadro crítico demonstrado por elementos como: a falência do padrão de acumulação; baixa na taxa de lucros; aumento das privatizações; a crise do Estado do bem-estar social; dentre outros elementos expostos pelo autor.

Quando o binômio produtivo taylorista/fordista se esgotou, foi necessário estabelecer um novo compromisso entre o capital e o trabalho que foi mediado pelo Estado. Este acordo assegurava ganhos sociais e de seguridade para os trabalhadores dos países do primeiro mundo, contanto que a temática do socialismo fosse esquecida, e ainda tinha como base explorar os trabalhadores do terceiro mundo que estavam excluídos do compromisso social democrata, ademais, também deveria abolir de seu território qualquer indício da ideologia socialista.

Assim, a atuação crescente da força produtiva provocou modificações na sociedade brasileira. Durante a ditadura civil militar houve um crescimento numérico da burguesia, entretanto, a classe proletária foi a que mais aumentou nos vinte e um anos do regime. Passou de 13,7\% em 1960 para 31,7\% na década de 1980. Germano (2011) explica que nesse contexto o capitalismo no Brasil assumiu uma identidade enormemente excludente e concentrada. Nas décadas de 1960 a 1980 houve um aumento da concentração da renda, sobretudo de 1970 
a 1972, anos do milagre econômico ${ }^{4}$, no qual os $10 \%$ mais ricos tinham uma renda média 60,2 vezes maior que os $60 \%$ mais carentes. Neste mesmo período, também ocorreu o aumento da dívida externa brasileira, que cresceu devido a elevação do preço do petróleo, em 1973. É dentro dessa circunstância que o Brasil, durante as décadas de 1960 e 1970, esteve inserido e passou a reformular o ensino superior e o ensino básico.

Este artigo busca fazer uma breve retrospectiva histórica acerca das mudanças ocorridas na educação brasileira nesse contexto, observando a legislação pertinente e suas reformulações, que alteraram a educação superior e deram um caráter profissionalizante à educação básica, especificamente ao ensino de $2^{\circ}$ grau, hoje denominado Ensino Médio.

\section{As alterações do ensino superior durante a ditadura civil militar}

O golpe civil militar estava em pleno recrudescimento no ano de 1968 quando foi determinada a reforma do ensino superior, mas a origem dessa reforma era anterior a esse ano e vinha sendo orientada por dois fatores, segundo Romanelli (2014): o aumento de novos empregos, com a implantação das indústrias de base na década de 1950 e o modelo de ascensão da classe média que aos poucos vinha se modificando.

Também é importante salientar que a demanda pela reforma não foi uma exigência do capital norte-americano, mas da própria sociedade brasileira, que via neste nível educacional um elemento de manutenção da estrutura social, quer fosse ela a permanência ou ascensão de classes, pois era esse nível de ensino que oportunizava as ocupações de altos graus hierárquicos tanto no setor público, quanto no privado. Havia uma cobrança da sociedade para aumentar a quantidade de vagas no ensino superior, porque a oferta de vagas era bem abaixo da procura. Sobre este aspecto, Romanelli (2014, p. 203) afirma que "a oferta, apesar de ter crescido, ficou aquém da demanda. Essa defasagem teve

\footnotetext{
${ }^{4}$ Segundo Habert (1996, p. 13-14), o chamado milagre econômico tinha três pontos basilares: "o aprofundamento da classe trabalhadora submetida ao arrocho salarial, às mais duras condições de trabalho e à repressão política; a ação do Estado garantindo a expansão capitalista e a consolidação do grande capital nacional e internacional; e a entrada maciça de capital estrangeiro na forma de investimentos e empréstimos." Essa expressão foi amplamente usada pela mídia no início da década de 1970, para fazer referência ao acelerado crescimento econômico brasileiro.
} 
seu ponto alto no acúmulo sustentável dos "excedentes", candidatos ao ensino superior que, embora aprovados nos exames vestibulares, não lograram classificação para as vagas oferecidas naquele nível".

Essa defasagem acontecia porque durante a década de 1960 o índice de crescimento do número de matrículas do ensino médio seguia na direção oposta ao do ensino superior e do primário. Enquanto no primeiro, o crescimento das matrículas no período de 1964 a 1968 foi de $69 \%$, o segundo aumenta apenas $52,76 \%$ e o terceiro é majorado em apenas $16 \%$, como demonstra Romanelli (2014).

A interferência dos EUA na educação brasileira, no entanto, já existia desde o final da Segunda Guerra Mundial, e um exemplo foi o programa Aliança para o Progresso e a Agência dos Estados Unidos para o Desenvolvimento Internacional (Usaid), que enviava recursos para a educação, inclusive para a região Nordeste. Embora essas influências norte-americanas tenham ocorrido no âmbito educacional, não podemos vê-las como elemento exclusivo da reforma universitária de 1968, pois, como esclarece Germano (2011, p. 106), "entendemos que a política educacional resulta da correlação de forças sociais existentes em determinado contexto histórico".

Para além da crise vivida pelo Estado, o governo tinha como um de seus objetivos centrais, segundo Ghiraldelli (2001, p. 172), "a substituição da ideologia nacionalista-desenvolvimentista pela ideologia do desenvolvimento com segurança [...]". Esses ideais justificavam a depreciação das instituições de ensino superior, pois era nesse espaço que se constituía um dos grandes polos de resistência ao regime da ditadura civil militar. É nesse contexto que o governo institui a Comissão Meira Matos no fim de 1967, guiado pela Teoria Geral da Administração de Empresas de Taylor e Fayol. O governo também criou, no início de 1968, com base no Decreto no 62.977/68, o Grupo de Trabalho da Reforma Universitária (GTRU).

O objetivo dessas comissões era encaminhar propostas que reformassem o ensino superior, para que o governo pudesse implantá-las e restabelecer o controle social. Os resultados desses estudos foram postos em prática com a implantação da Lei oㅜ 5.540, de 28 de novembro de 1968, que normatizou todo o ensino superior nacional. $\mathrm{O}$ aumento das matrículas no ensino superior ocorreu a 
datar do Decreto-lei o 405, de 31 de dezembro de 1968, conforme disposto em seu Art. 10: "O número de vagas fixado em editais de concursos vestibulares para ingresso em cursos de ensino superior poderá ser aumentado mediante simples publicação em diário oficial ou jornal de grande circulação local, [...]". (BRASIL, 1968).

A reforma do ensino superior de 1968 continua, claramente, a privilegiar as camadas sociais mais altas, apesar de aumentar o número das vagas neste nível de ensino, não era interesse do regime militar que as classes mais baixas ascendessem socialmente, assim, a modernização do ensino superior não favoreceu a uma verdadeira mobilidade social, uma vez que, de acordo com Germano (2011) a mudança ocorreu dentro de uma ordem, na qual se ajudaria os menos favorecidos sem modificar as estruturas sociais.

Para além dos elementos mencionados acima, o Estado também tinha um interesse no controle político e ideológico visando à inexistência da crítica social e política e adesão das diversas camadas sociais às políticas de Estado. A preocupação do governo era formar para desmobilizar os movimentos estudantis e sociais, tendo como um dos propósitos essenciais educar obedecendo às normas capitalistas. Outros principais propósitos para a educação, conforme Germano (2011), no período eram: estabelecer uma relação direta entre educação e trabalho; privatizar o ensino; estabelecer a profissionalização no ensino de $2^{\circ}$ grau.

A reforma proposta pela Lei oㅡ $5.540 / 68$ se deu em resposta a diversos movimentos sociais que pediam pelo aumento de vagas nas universidades e tinha como pressuposta finalidade a modernização e democratização do ensino superior, contudo, conforme afirma Germano (2011), o que ocorreu foi a despolitização e repressão às universidades. Entretanto, esse objetivo explícito indicava, na verdade, um outro que estava implícito, o de limitar a entrada das classes desfavorecidas às universidades. Assim, já ensaiaram a reforma do ensino de $2^{\circ}$ grau $^{5}$ nesta legislação. A Lei no $5.540 / 68$ tem relação com a reforma

\footnotetext{
${ }^{5}$ A Lei $n^{\circ} 5.692 / 71$ adotou a nomenclatura de $1^{\circ}$ e $2^{\circ}$ graus. No caso do ensino de $1^{\circ}$ grau ocorreu a fusão dos ramos do $1^{\circ}$ ciclo, dando ênfase à educação geral e propedêutica, porém havia a sondagem vocacional e a iniciação para o trabalho já neste período. Enquanto que o $2^{\circ}$ grau foi a fusão de todos os ramos do $2^{\circ}$ ciclo (o ensino normal, o ensino técnico industrial, o ensino técnico comercial e o ensino agrotécnico). As escolas de ensino médio passariam, obrigatoriamente, a fornecer cursos profissionais.
} 
do ensino médio sobre a qual discorremos adiante, posto que em seu Art. 21, parágrafo único, define como seria o concurso de vestibular a partir daquele momento:

Art. 21. O concurso vestibular, referido na lêtra a do artigo 17, abrangerá os conhecimentos comuns às diversas formas de educação do segundo grau sem ultrapassar êste nível de complexidade para avaliar a formação recebida pelos candidatos e sua aptidão intelectual para estudos superiores.

Parágrafo único. Dentro do prazo de três anos a contar da vigência desta Lei o concurso vestibular será idêntico em seu conteúdo para todos os cursos ou áreas de conhecimentos afins e unificado em sua execução, na mesma universidade ou federação de escolas ou no mesmo estabelecimento isolado de organização pluricurricular de acôrdo com os estatutos e regimentos. (BRASIL, 1968).

O parágrafo citado impõe a necessidade de vestibular para a entrada no ensino superior, o que, por si só, já é um processo seletivo que exclui uma maioria. Acrescenta ainda, que esse vestibular deveria conter todo o conteúdo das disciplinas gerais naquele e nos próximos anos consecutivos desde sua publicação.

Por fim, outro aspecto que deve ser levado em consideração é o fato da reforma de nível superior ter sido construída em consonância com os interesses do mercado de trabalho e para o desenvolvimento nacional. Os currículos e os cursos foram pensados e executados numa direção hegemônica, conforme disposto nos artigos 23 e 26 da Lei no 5.540/68:

Art. 23. Os cursos profissionais poderão, segundo a área abrangida, apresentar modalidades diferentes quanto ao número e à duração, a fim de corresponder às condições do mercado de trabalho.

$\S 1^{\circ}$ Serão organizados cursos profissionais de curta duração, destinados a proporcionar habilitações intermediárias de grau superior. [...]

Art. 26. O Conselho Federal de Educação fixará o currículo mínimo e a duração mínima dos cursos superiores correspondentes a profissões reguladas em lei e de outros necessários ao desenvolvimento nacional. (BRASIL, 1968). 
Nesse sentido, é possível notar que as universidades estariam formando o sujeito para que ele estivesse apto a corresponder às necessidades do mercado e do capital. A Lei trata de forma explícita essa característica do então ensino superior, quando dispõe, no citado parágrafo primeiro do artigo 23 , que haverá um currículo mínimo, cursos de curta duração e habilitações intermediárias. Este entendimento de que a educação deveria suprir e atender as demandas do mercado de trabalho foi proposta pelo GTRU. Segundo esse grupo, para diminuir o problema com o número de excedentes, deveria ser aumentado o número de vagas em cursos que desenvolvessem o país econômica e socialmente, como é o caso dos cursos da área da saúde e os de engenharia.

Mesmo com as modificações ocorridas no ensino superior com início na década de 1960, por meio da Lei oㅜ 5.540/68, esse nível de ensino continuará a cumprir seu papel de cunho capitalista e de continuidade das divisões das classes sociais. Esta reformulação não cumpre com o objetivo demandado pela coletividade civil brasileira, pois as universidades continuaram elitizadas e recebendo os sujeitos advindos das classes média e alta da sociedade. Então seria necessário fazer outras mudanças na área da educação para manter o controle social, já que o problema dos excedentes não fora realmente solucionado. Sobre essa outra reforma, que atinge a educação básica, especificamente o ensino médio, é que trataremos a seguir.

\section{A implantação do ensino técnico profissionalizante no cenário nacional a partir da promulgação da Lei 5.692/71}

O ensino profissionalizante universal e compulsório foi a solução encontrada para desviar o foco do público jovem que se candidatava ao ensino superior, pois o alvo desde então passou a ser o mercado de trabalho. Isto ocorreu com a implantação da Lei ํㅜ 5.692/71. Com essa reforma no ensino houve uma piora tanto no preparo dos candidatos para a entrada no ensino superior, quanto no próprio ensino médio, chamado a partir de então de $2^{\circ}$ grau. Para Cunha (2005), a produção flexível ${ }^{6}$ substitui o modelo taylorista/fordista,

\footnotetext{
${ }^{6}$ Para Harvey (1993, p. 140) a produção flexível, denominada por ele de acumulação flexível, "[...] é marcada por um confronto direto com a rigidez do fordismo, ela se apoia na flexibilidade dos processos de trabalho, dos mercados de trabalho, dos produtos e padrões de consumo. Caracteriza-se pelo surgimento de setores de produção inteiramente novos, novas maneiras de
} 
sendo crucial para o aparecimento de novos modelos educacionais. Isto demonstra a interferência da economia na educação.

Segundo Germano (2011), o projeto da Lei $n^{0} 5.692 / 71$ foi recebido no congresso com uma aceitação total e foi apoiado por professores. Também não houve disputas entre o setor privado e público da educação. Romanelli (2014) esclarece a existência de dois grupos distintos para se constituir a legislação que modificaria o ensino básico brasileiro. O primeiro grupo era a Usaid, que propunha uma reformulação apenas para a educação fundamental, denominado $1^{\circ}$ ciclo, partia do pressuposto de que a necessidade da indústria era de uma mão de obra com alguma escolaridade e algum tipo de treinamento que desse conhecimento básico ao sujeito sobre as técnicas de produção e com isto haveria o aumento da produtividade. Já o segundo grupo, composto pela Comissão Meira Matos e o GTRU, pensava em sanar o problema da crise estatal gerada pelos excedentes, assim, para eles seria mais interessante reformular $02^{\circ}$ ciclo, antigo ensino médio, denominado na Lei $n^{\circ} 5.692 / 71$ de $2^{\circ}$ grau.

O pensamento desse segundo seguimento era modificar o nível médio para deixá-lo de cunho profissionalizante e com caráter terminal. A terminalidade derivava da principal característica do ensino de $2^{\circ} \mathrm{grau}$, pois os alunos entrariam no mercado de trabalho com uma profissão reconhecida caso tivessem concluído o ensino profissionalizante. Acreditavam que o sujeito com uma profissão, quando concluísse o ensino médio, se contentaria em ingressar no mercado de trabalho e não sentiria estímulo para cursar o ensino superior, pois o nível médio já haveria proporcionado a formação profissional que antes só se obtinha com a conclusão de um curso universitário.

Dessa maneira, concordamos com Bourdieu (2011) ao entender a escola como um elemento de conservação social, legitimadora das desigualdades sociais e isto contraria a ideia de uma escola libertadora. Para ele existe o elemento da desigualdade no acesso superior para as diferentes camadas sociais, considerando que os mecanismos do privilégio cultural são percebidos apenas quando aparecem em grosseria demasiada. Ao longo do regime militar,

fornecimento de serviços financeiros, novos mercados e, sobretudo, taxas altamente intensificadas de inovação comercial, tecnológica e organizacional. A acumulação flexível envolve rápidas mudanças dos padrões do desenvolvimento desigual, tanto entre setores como entre regiões geográficas, criando, por exemplo, um vasto movimento no emprego no chamado "setor de serviço", bem como conjuntos industriais completamente novos [...]". 
notamos abertamente esse caráter elitista e de divisão social no sistema de educação. Enquanto uns, classes burguesa e média, poderiam e deveriam ir para o ensino superior, outros, camadas mais pobres, teriam que se contentar com lugares sem nenhum privilégio ou sem grandes possibilidades de ascensão social, corroborando o ideário de uma escola conservadora dos padrões burgueses sociais.

A concepção de educação na Lei nํ 5.692/71 também é, a exemplo da legislação do ensino superior, para atender as demandas do sistema econômico. Esse modelo tem suas bases na Teoria do capital humano. Esse conceito, de cunho liberal, foi desenvolvido no final da década de 1950 e década de 1960 por economistas ingleses e norte-americanos que tinham por preocupação central tornar a educação e o desenvolvimento econômico compatíveis com a distribuição de renda, de maneira a excluir qualquer questionamento que pudesse ser projetado contra a forma de produção do capital. Dessa forma, essa teoria deve ser entendida como o investimento em educação, em especial na educação formal, que o capital humano faz para se qualificar e desenvolver suas habilidades cognitivas que passam a interferir diretamente na sua produtividade, e esta última na sua renda.

Schultz (1967) esclarece que a produção provém da instrução, investir em habilidades e conhecimentos significa ter sua renda aumentada no futuro. Nesta perspectiva, o fator econômico explica o ingresso e permanência nas escolas, assim como o rendimento escolar. Para ele "o investimento nos assuntos escolares, no treinamento realizado no trabalho, na saúde, na informação de emprego e na migração possibilitam a produtividade de valor das capacidades adquiridas do homem [...]." (SCHULTZ, 1973, p. 26). É possível perceber que tal postura conduz a uma produtividade que tanto alarga as possibilidades de renda e sucesso do trabalhador, quanto contribui para o desenvolvimento do capital. Isso ocorre porque a educação capacita o homem, que passa a produzir mais. Dessa forma, o sujeito aumenta a sua renda e por consequência o crescimento do capital da nação.

Diante disso, podemos esclarecer algumas críticas feitas à Teoria do capital humano. Conforme Lima (1980), a primeira delas é o fato dessa concepção desconsiderar as características e habilidades que o sujeito traz 
consigo para dentro das instituições de ensino, fragilizando, assim, a questão das habilidades cognitivas ensinadas pelas escolas o que resultaria na mesma renda, caso a escolaridade formal fosse a mesma, pois uns tem mais habilidades para as artes, já outros para os números, dessa forma, as habilidades pessoais e individuais dos sujeitos interferem diretamente na sua produção $e$ consequentemente na renda. Outro ponto exposto pelo autor, é o fato da mesma escola preparar pessoas de origens diversas para executarem tarefas distintas.

Conforme Bourdieu (2011), podemos destacar que o capital cultural do sujeito também interfere no êxito ou no insucesso escolar da criança, igualmente como se relaciona com o próprio nível cultural da família. Segundo o autor, as variações existem até mesmo se os pais são de origens distintas e desiguais. Partindo dessa concepção, como atribuirmos à escola todos os resultados que se obtém ao longo da vida? Além disso, e sabendo das peculiaridades existentes em cada sujeito, como generalizar e conferir ao indivíduo a responsabilidade do seu insucesso, uma vez que a escola "repassa todo o conhecimento" para desenvolver as habilidades cognitivas necessárias para desempenhar uma produtividade homogênea entre os pares?

É óbvio que tais relações e atribuições feitas ao sistema de ensino e ao indivíduo são demasiadamente incoerentes. Cada sujeito trabalha de acordo com suas aptidões individuais, se diferencia do outro até mesmo pela própria fisiologia do seu corpo. Portanto, se percebe que esta educação explicitada por Schultz (1973) não considera a complexidade do humano, apenas serve para instrumentalizar o homem com as capacidades necessárias para desenvolver tecnicamente uma determinada função. Dessa forma, além desse sistema educativo reproduzir as relações sociais de produção do capital, passa a ser um elemento que se articula com o movimento capitalista.

De conformidade com a Teoria do capital humano, podemos analisar a Lei no 5.692/71 relacionando-a à teoria. Vertentes pedagógicas como instrumentalizar, treinar, preparar para o mercado de trabalho, em consonância com o sistema econômico, eram dos principais objetivos da reforma de $2^{\circ}$ grau. A constituição da Lei $n^{0}$ 5.692/71 foi pensada baseada em uma perspectiva de desenvolvimento da economia nacional. São três seus objetivos centrais, conforme afirma Kuenzer (2000): contenção dos estudantes para ingressarem no 
ensino superior; despolitização do ensino de $2^{\circ}$ grau; preparação da força de trabalho para suprir as demandas econômicas nacionais, auxiliando dessa forma, o seu crescimento.

O primeiro artigo da Lei $n^{\circ} 5.692 / 71$ dispõe os seguintes elementos: "Art. $1^{\circ}$ O ensino de $1^{\circ}$ e $2^{\circ}$ graus tem por objetivo geral proporcionar ao educando a formação necessária ao desenvolvimento de suas potencialidades como elemento de auto-realização, qualificação para o trabalho e preparo para o exercício consciente da cidadania" (BRASIL, 1971, grifo nosso).

São três os elementos em destaque, o primeiro deles tem por finalidade: desenvolver as potencialidades dos discentes para a autorrealização. Mas, como fazer isso se cada ser humano é único, como atingir e manter esse patamar de realização pessoal? Neste momento, é possível notar as influências da teoria da autorrealização de Maslow (1973) ${ }^{7}$, assim também como a teoria do capital humano, no que diz respeito ao desenvolvimento das potencialidades do sujeito, pois essas seriam usadas pelas indústrias para o crescimento do sistema econômico juntamente com a qualificação para o trabalho.

O segundo ponto exposto no artigo é "qualificação para o trabalho", em que a relação entre educação e produtividade demonstra que essa proposta de ensino prepararia o aluno predominantemente para o trabalho manual, pois essa educação se preocupava em formar técnicos para ingresso no mercado de trabalho em todos os espaços da economia. Conforme situa Saviani (2007, p. 157)

[...] após o surgimento da escola, a relação entre trabalho e educação também assume uma dupla identidade. De um lado, continuamos a ter, no caso do trabalho manual, uma educação que se realizava concomitantemente ao próprio processo de trabalho. De outro lado, passamos a ter a educação de tipo escolar destinada à educação para o trabalho intelectual.

\footnotetext{
${ }^{7}$ Essa teoria prega que o homem hierarquiza suas necessidades do nível mais baixo para o mais alto, assim sempre tentará suprir primeiramente os níveis mais elementares, para só então buscar os graus superiores para sua realização. Segundo Maslow, existem cinco níveis da necessidade humana: as fisiológicas; as necessidades de garantia; as necessidades de pertinência e de amor; as necessidades de estima; e por fim, da autorrealização.
} 
Essa "qualificação para o trabalho" vai mais à frente remeter às necessidades do mercado e não do sujeito, como podemos observar disposto na Lei $n^{\circ} 5.692 / 71$

1 O Observadas as normas de cada sistema de ensino, o currículo pleno terá uma parte de educação geral e outra de formação especial, sendo organizado de modo que:

a) no ensino de primeiro grau, a parte de educação geral seja exclusiva nas séries iniciais e predominantes nas finais;

b) no ensino de segundo grau, predomine a parte de formação especial.

2ำ A parte de formação especial de currículo:

a) terá o objetivo de sondagem de aptidões e iniciação para o trabalho, no ensino de $1^{\circ}$ grau, e de habilitação profissional, no ensino de $2^{\circ}$ grau;

b) será fixada, quando se destina a iniciação e habilitação profissional, em consonância com as necessidades do mercado de trabalho local ou regional, à vista de levantamentos periodicamente renovados. (BRASIL, 1971, grifo nosso).

Os trechos destacados acima, no texto da lei, evidenciam duas características do ensino de $2^{\circ}$ grau. A primeira é a relação economia/educação, ao abordar que a iniciação para a habilitação profissional suprirá as necessidades do mercado trabalho e não as do trabalhador. Verificamos, de forma clara, que essa proposta pedagógica condiz com a Teoria do capital humano, pois os investimentos educacionais no sujeito desaguariam para o crescimento da economia nacional. Já a segunda característica, diz respeito à fragmentação do processo de ensino-aprendizagem, uma vez que separa as disciplinas do currículo geral das disciplinas técnicas.

Apesar do ensino de $1^{\circ}$ grau elencar como prioridade a educação geral, seu objetivo era a sondagem das aptidões e iniciação para o trabalho, ou seja, apesar de tratar o currículo propedêutico durante os oito anos de duração, o ensino de $1^{\circ}$ grau teria como direção sondar as aptidões laborais dos discentes, assim facilitando seu ingresso no $2^{\circ}$ grau de maneira direcionada para determinada área do conhecimento, ou ainda, colocando o aluno já no mercado. Notamos, dessa forma, a convergência entre esses níveis de ensino e a sua relação com o sistema econômico, pois os alunos não tinham muitas possibilidades ou escolhas, devido ao ensino, principalmente na esfera estadual, sofrer com ausência de recursos materiais e humanos. Cunha (2005) chama a 
atenção para os estados e municípios terem dado ênfase ao quantitativo da reforma, devido à carência dos elementos materiais e humanos. Sobre a antecipação para o trabalho, a Lei n 5.692/71 dispõe da seguinte maneira: "Art.

76. A iniciação para o trabalho e a habilitação profissional poderão ser antecipadas [...]". (BRASIL, 1971).

O Art. 76 regulamenta a inserção antecipada no mercado de trabalho sob a justificativa da necessidade do próprio indivíduo ou pela ausência de recursos do Estado. O objetivo do ensino de $1^{\circ}$ grau também era a iniciação para o trabalho e a sondagem das aptidões, que de certa maneira concorda com a Teoria do capital Humano, pois essa sondagem levaria o aluno para uma determinada área profissional que os professores acreditassem ser mais adequada. Já no ensino de $2^{\circ}$ grau, quem regularia a parte diversificada do conteúdo seriam as necessidades do mercado de trabalho, esse norte seria conduzido pelos levantamentos periódicos regulamentados pela Lei no $5.692 / 71$.

O último elemento trazido pelo artigo primeiro da Lei $n^{0} 5.692 / 71$ expressa que a educação profissionalizante também deveria preparar o discente para 0 "exercício consciente da cidadania" que, neste momento, talvez significasse obedecer aos preceitos e as bases ideológicas do regime militar, regidas pela Doutrina de Segurança Nacional. ${ }^{8}$

Para Borges (2007, p. 30), “[...] não resta a menor dúvida de que a Doutrina põe em risco a defesa dos direitos humanos, pois exclui os pressupostos mínimos da cidadania”. Explica ainda que, quando não é possível detectar os inimigos do Estado ou que atividades podem ser concretizadas, todos os cidadãos são considerados suspeitos e culpados até provar sua inocência. Dessa forma, podemos entender que a escola deveria preparar o sujeito para obedecer ao Estado militar sem questionamentos ou manifestações contrárias ao seu querer.

Como afirmou Gamboa (2001), o sistema educativo desde a década de 1970 produziu o capital humano sob uma ótica pedagógica de eficiência

\footnotetext{
${ }^{8}$ A Doutrina de Segurança Nacional foi criada durante a Guerra Fria e provê informações para se implementar e manter um Estado forte ou uma ordem social estipulada, tendo por base quatro conceitos: os objetivos nacionais; o poder nacional; a estratégia nacional; e a segurança nacional. Segundo Borges (2007, p. 24) "objetivamente, a Doutrina de Segurança Nacional é a manifestação de uma ideologia que repousa sobre uma concepção de guerra permanente e total entre o comunismo e os países ocidentais". O autor explica ainda que a sua essência "[...] reside no enquadramento da sociedade nas exigências de uma guerra interna, física e psicológica, de característica antissubversiva contra o inimigo comum." (BORGES, 2007, p. 29).
} 
instrumental, os objetivos do ensino-aprendizagem foram reduzidos ao adestramento. A legislação que compõe a reforma do ensino básico brasileiro segue esse modelo. A educação separou o trabalho manual do trabalho intelectual. Esse modelo educativo majorou ainda mais o grande fosso entre as camadas sociais e aumentou a dualidade já existente nos sistemas de ensino brasileiro.

Aparentemente, a implantação do $2^{\circ}$ grau, com a promulgação da Lei ํㅜ $5.692 / 71$, não foi como esperado. Os estados não estavam prontos para cumprir com as exigências do ensino profissional, havia escassez de professores para atuar nas diversas áreas de conhecimento, os cursos postos em prática geralmente eram em áreas que não tivessem necessidades de laboratórios ou bibliotecas com materiais específicos para a continuidade das habilitações, como por exemplo: Técnico de contabilidade ou Auxiliar de Contabilidade, Técnico em Administração, Magistério, dentre outros. No tópico seguinte iremos abordar alguns desses entraves e como isso influenciou a sociedade brasileira.

A implantação da Lei ํㅜ 5.692/71 foi prevista para acontecer de maneira gradual, de acordo com a disponibilidade dos recursos materiais, humanos e didáticos, pois já antevia que seus objetivos não seriam alcançados em curto prazo devido à escassez desses recursos, na prática, a reforma priorizou a extensão escolar obrigatória, considerando apenas o núcleo comum do currículo (Comunicação e Expressão, Estudos Sociais e Ciências).

A Lei $n^{\circ} 5.692 / 71$ normatizou tanto o ensino regular quanto o supletivo. $O$ ensino regular era composto pelos sistemas de ensino municipais e estaduais de $1^{\circ}$ e $2^{\circ}$ graus e o ensino superior federal. Já o supletivo abarcava o Movimento Brasileiro de Alfabetização (MOBRAL), o Projeto Minerva (educação pelo rádio), televisões educativas, o Serviço Nacional de Aprendizagem Industrial (SENAI) e Serviço Nacional de Aprendizagem Comercial (SENAC), dentre outros. O ensino supletivo era destinado aos maiores de 14 anos que não haviam concluído os estudos na faixa etária regular ou aqueles que haviam completado $01^{\circ} \mathrm{grau}$, mas não haviam cursado ou completado $02^{\circ}$ grau e também oferecia 0 ensino de educação profissional.

No que diz respeito ao $1^{\circ}$ grau, Germano (2011) expõe que ocorreu a expansão de 40\% das matrículas nas escolas entre 1973 e 1985, apesar de 15\% 
do público entre 7 e 14 anos nunca ter tido acesso à escola, conforme dados de 1985. A rede pública concentrava mais de $80 \%$ das matrículas no ensino de $1^{\circ}$ grau nesse período. Esta ampliação se caracteriza pela diminuição da quantidade de tempo na escola e o aumento dos turnos. Também houve aumento na quantidade de professores leigos no $1^{\circ} \mathrm{grau}$, principalmente no Nordeste.

São dois os elementos problemáticos expostos anteriormente. O primeiro deles foi a necessidade de diminuir o tempo na escola para ampliar as quantidades de séries. A ampliação das séries exigia uma mudança profunda na estrutura da educação de $1^{\circ}$ grau, nesta perspectiva, fica uma indagação: até que ponto realmente foi positiva essa mudança para a estrutura de ensino? Entendemos como ponto positivo a elevação da escolaridade de 4 para 8 anos e a eliminação dos exames de admissão que eram exigidos para a passagem do primário ao ginásio. Muitos alunos não avançavam para as séries superiores devido a essa avaliação. Com a Lei no 5.692/71, esse exame foi eliminado.

Entretanto, Frigotto (2010a) destaca que o alongamento da escolaridade é necessário ao capital, pois a escola será um lugar que ocupa cada vez mais um número maior de pessoas em tempos ainda igualmente longos. $A$ instituição de ensino não produz a mais-valia, entretanto, é necessária ao capitalismo para realizá-la. A escola deve pensar o trabalho como princípio educativo e, para se resolver esta questão educacional, Frigotto (2010a, p. 220) explica:

é pelo trabalho que o homem - e todo homem - encontra sua forma própria de produzir-se em relação aos outros homens. [...] não há razões de outra espécie, a não ser históricas, que justifiquem relações sociais de produção da existência humana onde haja proprietários dos meios e instrumentos de produção, e aqueles que têm apenas a posse relativa de sua força de trabalho.

Nessa perspectiva, segundo os princípios de Gramsci (1979), a escola não deve ser desinteressada, mas formar e desenvolver as capacidades humanas tanto intelectuais como manuais. A escola deve ser única e ter o trabalho como princípio educativo, constituindo, assim, na práxis educativa uma relação dialética entre a política e a técnica.

A segunda questão diz respeito ao fato do aumento de professores sem a habilitação necessária para atuar em sala de aula, já que se elevou o número de profissionais com apenas o $1^{\circ}$ grau e a Lei $n^{\circ}$ 5.692/71 previa, em seu Art. 30, 
formação mínima para atuar " a) no ensino de $1^{\circ}$ grau, da $1^{\text {a }}$ à $4^{\mathrm{a}}$ séries,

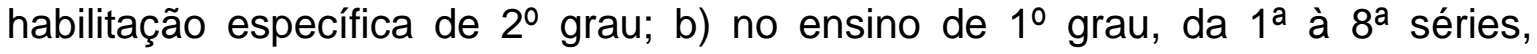
habilitação específica de grau superior, ao nível de graduação, representada por licenciatura de $1^{\circ}$ grau obtida em curso de curta duração;" (BRASIL, 1971).

No que tange ao ensino de $2^{\circ}$ grau houve, de acordo com Cunha (2005), a elaboração dos currículos pela Universidade do Trabalho de Minas Gerais (Utramig), que se transformou, desde 1971, no Laboratório de Currículo do Departamento do Ensino Médio. Dos 52 currículos produzidos, 32 eram para a indústria. A escolha das disciplinas da parte especial para cada sistema de ensino ficaria a cargo do Conselho Estadual de Educação (CEE), contudo as escolas poderiam escolher quais disciplinas fariam parte do currículo diversificado.

Houve diversas campanhas de enaltecimento do ensino profissionalizante, na tentativa de diminuir a valoração dada ao ensino superior quando relacionado ao ensino profissional. Uma dessas campanhas resultou no Caderno de Profissões, convergindo para um discurso de reconhecimento do ensino técnicoprofissionalizante. Germano (2011) afirma que, apesar do discurso das autoridades irem no sentido de uma busca pela equidade social, o que realmente importava nessa política educacional era a manutenção da desigualdade social ao constituir relação direta com a produção capitalista.

Frigotto (2010b) esclarece que a partir da década de 1970, quando o economicismo passou a se relacionar mais diretamente com a educação e foi reforçado pelos ideais do regime militar, houve diversos resultados negativos. $O$ primeiro deles é o fato de ter sido enfatizada a ideia da educação como negócio; o segundo diz respeito ao dualismo educacional entre a classe trabalhadora e a classe dominante; o terceiro foi a fragmentação do processo de conhecimento.

Assim, este modelo educativo acabou por aumentar ainda mais a dualidade educacional do país à época, uma vez que levou a uma migração da classe média para as escolas privadas, pois não havia interesse, por parte desse grupo, em uma educação para o trabalho manual, mas em ingressar nas universidades do país, como já foi esclarecido anteriormente. A classe mais pobre teve que se contentar com o ensino técnico-profissionalizante. 
Moura (2007) destaca que a Lei $n^{\circ} 5.692 / 71$, ao tornar a profissionalização compulsória, deveria ter extinguido a dualidade já existente na educação brasileira, mas ocorreu o contrário "[...] na prática, a compulsoriedade se restringiu ao âmbito público, notadamente nos sistemas de ensino dos estados e no federal. Enquanto isso, as escolas privadas continuaram, em sua absoluta maioria, com os currículos propedêuticos [...] visando o atendimento às elites." (MOURA, 2007, p. 12).

Dessa maneira, a burguesia cumpriria o outro papel, ocupando as funções intelectuais do mundo capitalista. Isso decorre do fato das escolas privadas não terem sido obrigadas a aderir ao ensino de cunho profissional. A burguesia, apoiando-se na Lei oㅜ 5.692/71 e na sua interpretação ambígua, desconsidera a Educação Profissional e continua promovendo para seus filhos um ensino propedêutico e preparatório ao exame de vestibular, à época composto por disciplinas gerais, conforme disposto na Lei oㅜ 5.692/71. Já as escolas públicas, estaduais e municipais, não tinham material didático e humano suficiente para efetivarem uma educação de qualidade. Conforme afirma Germano (2011, p.190), "A reforma educacional do Regime foi particularmente perversa com o ensino de 2 o grau público. Destruiu o seu caráter propedêutico ao ensino superior, elitizando ainda mais o acesso às universidades públicas. Ao mesmo tempo, a profissionalização foi um fracasso".

É nesta diferenciação entre ensino público e privado que se baseia a dualidade do sistema de ensino brasileiro no período estudado, entretanto, é preciso esclarecer que as escolas técnicas federais não se incluíam nesta educação precária, pois dispunham do aparato necessário para pôr em prática de maneira efetiva 0 ensino profissional de $2^{\circ}$ grau. Todavia, essa política educacional sobrecarregou as escolas técnicas federais, pois muitos alunos das redes municipal e estaduais faziam apenas as disciplinas de caráter profissional nas escolas federais, aumentando o número de alunos atendidos por essa rede de ensino, conforme afirma Cunha (2005).

A manutenção do sistema para que cada indivíduo ocupasse, na esfera social, o papel que foi determinado em consequência do seu nascimento, ficou ainda mais intensa. Uma vez implantado o ensino técnico-profissionalizante, houve uma diferenciação não apenas no quesito qualidade de ensino, mas essa 
diferença passou a atingir o próprio modelo educacional, sendo um padrão praticado nas escolas privadas e para sua elite e outro destinado à instituição pública e para os pobres.

Assim, podemos afirmar que um dos interesses da reforma do ensino superior foi atingida, o de manter as universidades públicas com uma oferta menor do que o necessário e manter essas vagas ocupadas pelas classes médias e altas da sociedade. Os pobres que quisessem cursar uma universidade teriam que migrar para o ensino privado, pois não Ihes eram proporcionadas condições didáticas, de conhecimentos necessários para disputar igualmente com os que haviam estudado o ensino de $2^{\circ}$ grau nas escolas particulares. Conforme Freitag (2005, p. 142), "o fortalecimento do ensino particular tem de ser visto como uma barreira socioeconômica, legalizada e sancionada por lei, que prejudicará as classes economicamente desfavorecidas".

Além dessas dificuldades expostas, os alunos das escolas públicas também enfrentaram outros problemas referentes à precarização do ensino de $2^{\circ}$ grau. Cunha (2005) elenca algumas das razões desses problemas: 0 ensino de $2^{\circ}$ grau sofreu pela ausência de recursos humanos e materiais; os prédios eram adaptados; os espaços muitas vezes não estavam disponíveis; alguns administradores escolares passaram a cobrar taxas, pois esse nível de ensino não estava posto legalmente como gratuito até então. Somando-se a esses pontos, Germano (2011) expõe o fato das escolas não formarem nem mesmo para os requisitos industriais, pois o ensino não preparava realmente para as necessidades das indústrias.

Diante dessas fragilidades, algumas resistências passaram a acontecer: os alunos não aceitaram de forma passiva a reforma do ensino profissionalizante, pois esta diminuía a carga horária das disciplinas gerais de interesse de todos para entrada no ensino superior; também se manifestaram contrários às taxas cobradas nas escolas públicas para financiamento do ensino técnicoprofissionalizante - essas críticas foram veiculadas em meios diversos como jornais e festas de formaturas -; os diretores das escolas, especialistas em educação, criticavam a viabilidade do ensino profissionalizante universal e compulsório no $2^{\circ}$ grau; e as escolas privadas combateram a reforma, devido seus altos custos. Dessa maneira, para conter a oposição e a opinião pública, o 
governo militar inicia, já em 1972, algumas medidas para assegurar a implantação da reforma de $1^{\circ}$ e $2^{\circ}$ graus.

O Parecer no 45/72, apresentado por Valnir Chagas, tomou por fundamento as análises da Utramig, e foi composto por sete tópicos, sendo que trataremos especificamente do primeiro deles, que traz considerações acerca da filosofia educacional da época (tecnologia versus humanismo). Ele também dispõe sobre as habilitações profissionais, seus currículos e o mínimo exigido para cada capacitação.

As considerações trazidas no primeiro item do Parecer no $45 / 72$ são para reforçar a ideia de que o humanismo e a tecnologia não são opostos, mas se complementam, assim como o humanismo forma para a cultura acadêmica, a tecnologia também o faz. O Parecer desmistifica a concepção de que o cristianismo é contrário às tecnologias, colocando o humanismo ou o renascimento clássico, até certa medida, como anticristão, ao mesmo tempo em que glorifica o trabalho manual do homem, usando como exemplo o fato de Cristo ter sido carpinteiro.

É notória, no Parecer ํำ45/72, a exaltação ao trabalho manual e aos benefícios que as tecnologias trariam para o sujeito que optasse por uma educação de cunho tecnológico. Essa necessidade de majorar a educação profissional advém da desvalorização do trabalho manual. A associação constituída com o cristianismo é pertinente, pois induzindo o sujeito por meio de sua religiosidade, apela para o emocional e descarta o racional. Como o Brasil sempre foi um país de maioria cristã, essa técnica foi adequada, se considerarmos que tal ação persuadiu grande número de devotos.

Cunha (2005) indica que, com o objetivo de conter a entrada no ensino superior, esse Parecer também evidencia a possibilidade de poder antecipar a formação especial para ingressar no mercado de trabalho, mas o ensino propedêutico não poderia ser abreviado em função da entrada no ensino superior. Podemos analisar, nesse sentido, que este é um, dentre os vários paradoxos ou ambiguidades expressos na legislação que reformulou o ensino básico brasileiro no período da ditadura civil militar.

Já o Parecer № 76 de 23 de janeiro de 1975, também expedido pelo Conselho (CFE), relatado por Terezinha Saraiva, reorientou a política educacional 
expondo não ser viável que todas as escolas se transformassem em técnicas, conforme expresso em seu texto, "O equívoco, a nosso ver, está no entendimento de que toda escola de $2^{\circ}$ grau deve ser equipada para oferecer ensino técnico e profissional. A lei não diz, em nenhum momento, que a escola de $2^{\circ}$ grau deve ser profissionalizante e sim, que o ensino de $2^{\circ}$ grau é que o deve ser." (BRASIL, 1975, grifo do documento).

Neste sentido, não seria necessária uma substituição do ensino geral pelo profissional no espaço físico da própria escola, mas poderia haver uma parceria entre os sistemas de ensino estaduais e federais, entre empresas e entidades que já ofereciam o ensino técnico. Essa nova instrução desobriga as escolas particulares de implantar o ensino profissional, permitindo que a parte profissionalizante do currículo acontecesse em parceria com outras instituições de ensino.

Ao mesmo tempo, o Parecer no 76/75 também modifica o entendimento de ensino profissionalizante trazido pela Lei no 5.692/71. Ao invés de ser um conhecimento técnico e limitado, o Parecer passa a defender o ensino profissionalizante como orientação ao jovem para o domínio de atividades científicas, aplicação de tecnologia dos conhecimentos abstratos. Ao invés de uma educação profissionalizante específica, passou a ser básica e geral. Acompanhemos essa disposição do Parecer nำ 76/75:

\begin{abstract}
A educação profissionalizante não se limita, porém, à transmissão de um conhecimento técnico limitado e pouco flexível muito menos de atividades. Não se pretende de outro lado que todas nossas escolas se transformem em escolas técnicas, o que seria desnecessário e economicamente inviável. [...]. Através da educação profissionalizante o que se pretende é tornar o jovem consciente do domínio que deve ter as bases científicas que orientam uma profissão e levá-lo à aplicação da tecnologia dos conhecimentos meramente abstratos transmitidos até então, pela escola. (BRASIL, 1975).
\end{abstract}

O texto deixa claro que a educação específica seria fornecida pelo ensino superior e o ensino de $2^{\circ}$ grau ofereceria uma formação básica e de caráter geral. Além desses pontos já expostos, o Parecer no 76/75 considera algumas disciplinas da parte geral como sendo componentes do conjunto de conteúdos da 
parte especial, que também seriam base para habilitar o sujeito para a profissionalização.

Com essa nova perspectiva de que o ensino profissional não seria mais universal e compulsório, ficava mais difícil ainda mantê-lo nos moldes iniciais. Com base nessas divergências e questionamentos é que se editam os Pareceres no 860/81 e no 177/82. Esses dois pareceres partem do mesmo pressuposto: era necessário alterar a Lei no 5.692/71 e consequentemente o ensino técnicoprofissionalizante de $2^{\circ}$ grau.

O Parecer nํ 177, aprovado em 31 de março de 1982, foi resultado dos relatórios elaborados pelos dois Grupos de Trabalho do Ministério de Educação (MEC) e CFE, sua relatora foi Anna Bernardes da Silveira. A principal mudança que esse parecer editou foi o fato de manter a capacitação profissional para o $2^{\circ}$ grau, porém, iria predominar a parte geral ou a especial, ou ainda iria ocorrer uma proporcionalidade entre esses dois currículos, a depender de cada escola.

O Parecer no $177 / 82$ sugere a substituição da palavra qualificação por preparação, ficando o texto da Lei $n^{\circ} 5.692 / 71$ disposto da seguinte forma: "Art. $1^{\circ}$ - O ensino de $1^{\circ}$ e $2^{\circ}$ graus tem por objetivo geral proporcionar ao educando a formação necessária ao desenvolvimento de suas potencialidades como elemento de auto-realização, preparação [...].” (BRASIL, 1971, grifo nosso). Assim, fica claro que a preparação para o trabalho deveria fazer parte da formação integral do aluno, independente do mesmo optar por uma habilitação profissional ou não.

Esses vários dispositivos postos em pauta desde a promulgação da Lei no 5.692/71 culminaram na Lei $n^{0} 7.044$ de 18 de outubro de 1982. As alterações produzidas por esse dispositivo legal apenas regulamentaram as propostas trazidas pelos Pareceres no 860/81 e o no 177/82. A Lei ํㅜ 5.692/71 continuava válida quase integralmente, pois sofrera algumas modificações trazidas pela Lei nº 7.044/82. Uma das principais mudanças foi a substituição do termo qualificação por preparação, como foi já exposto anteriormente. Sobre os currículos para o $1^{\circ}$ e $2^{\circ}$ graus, a Lei no 7.044/82 dispõe da seguinte forma:

$\S 1^{\circ}$ - A preparação para o trabalho, como elemento de formação integral do aluno, será obrigatória no ensino de $1^{\circ}$ e $2^{\circ}$ graus $e$ constará dos planos curriculares dos estabelecimentos de ensino. 
$\S 2^{\circ}$ - À preparação para o trabalho, no ensino de $2^{\circ}$ grau, poderá ensejar habilitação profissional, a critério do estabelecimento de ensino. (BRASIL, 1982, grifo nosso).

O parágrafo primeiro deixa claro que a formação integral do aluno acarreta obrigatoriamente a preparação para o trabalho, no entanto, o parágrafo segundo esclarece que essa preparação poderia ou não habilitar para uma profissão no ensino de $2^{\circ}$ grau, ou seja, nesta nova perspectiva, preparar para o trabalho não significava necessariamente obter uma profissão ao final do ensino de segundo grau, entretanto, esses alunos deveriam sair do nível básico de ensino preparados para atuar no mercado de trabalho. A começar daí o ensino profissional ficava a cargo das instituições escolares, não sendo mais compulsório e obrigatório.

Outro ponto bastante relevante trazido pela Lei oㅜ 7.044/82 é a exclusão da sondagem das aptidões para o trabalho no ensino de $1^{\circ}$ grau, porém a nova legislação não traz nenhum novo objetivo para este grau de ensino a não ser o já exposto: preparar para o trabalho. Mais uma mudança importante foi o fato do mercado de trabalho deixar de regular o currículo da parte especial no $2^{\circ}$ grau de acordo com suas necessidades, por meio de levantamentos periódicos. A regulamentação trazida pela Lei $n^{\circ} 7.044 / 82$ estabeleceu que "b) as matérias que comporão a parte diversificada do currículo de cada estabelecimento serão escolhidas com base em relação elaborada pelos Conselhos de Educação, para os respectivos sistemas de ensino;" (BRASIL, 1982).

Essas são as alterações mais importantes sob o nosso ponto de vista, porém, outras mudanças também foram impostas pela Lei ํํ 7.044/82. Como já foi dito, a Lei $n^{0} 5.692 / 71$ continuava valendo. Cunha (2005) explica que os cursos de tecnólogos vieram para suprir o fracasso do ensino profissionalizante, pois não houve diminuição da demanda dos cursos superiores em função do ensino profissionalizante. Os exames vestibulares tiveram algumas modificações devido a essas reformulações trazidas pela Lei ํㅜ 7.044/82. Os sistemas de ensino brasileiro só voltariam a passar por modificações estruturais posteriormente, com a constituição da Lei de Diretrizes e Bases de 1996. 


\section{Considerações finais}

Diante dos fatos até aqui expostos, podemos dizer que as reformas do ensino superior e médio se entrelaçaram e foram feitas, em especial a segunda, em razão da primeira. Uma seria condicionante da outra, porém, o que regeu as duas reformulações em um sentido mais amplo foi a economia e as necessidades do mercado. O sistema econômico brasileiro vinha passando por diversas mudanças desde o processo de internacionalização do mercado, quando os bens de consumo duráveis passaram a ser produzidos dentro do país.

Ao assumirem o poder, em 1964, os militares fortificaram esse modelo hegemônico, tendo como os grandes consumidores desses produtos a burguesia nacional e alguns setores da classe média, enquanto a classe subalterna foi excluída desse movimento político e econômico. A fonte de controle que o Estado militar usava para dominar essa camada social mais pobre eram as políticas educacionais, que passam a servir aos interesses da economia desde as reformulações de ensino e viabilizando sua funcionalidade. Neste sentido, Freitag (2005, p. 61) explica que "a escola contribui, pois, de duas formas, para o processo de reprodução da formação social do capitalismo: por um lado reproduzindo forças produtivas, por outro lado, as relações de produção existentes".

Não obstante, o que importa chamar a atenção é o fato da reforma de ensino superior já legislar sobre o aspecto do conteúdo geral para o exame dos vestibulares e logo em seguida, três anos depois, promulgarem uma legislação que, ao invés de sanar o problema da crise social - oportunizando o ingresso de todos nas universidades - aumentaria ainda mais o fosso da desigualdade social existente à época. Assim, Aranha (1996) nos faz refletir, indicando quem entraria nas melhores universidades e, quem, ao fim, ocuparia as elevadas posições na sociedade brasileira.

Para Cunha (2005), o grupo que reformulou o ensino superior já o fez baseado em conclusões que se referenciavam de forma direta ou indireta ao ensino de $2^{\circ}$ grau. Este grupo estabeleceu os seguintes princípios: os recursos para o ensino superior não deveriam ser ilimitados para não prejudicar o acolhimento demandado do ensino primário e médio; e deveria haver um 
crescimento equilibrado entre os três níveis de ensino: primário, médio e superior. Nesse equilíbrio, os dois primeiros níveis atenderiam a quase toda a população enquanto as universidades seriam para quem quisesse e pudesse. Esses princípios eram contrários à demanda social pelo aumento de vagas no ensino superior. A expansão seria controlada e levaria em conta o aumento demográfico e social.

Notamos, dessa forma, que o ensino técnico-profissionalizante só perde espaço já no processo de abertura do governo militar. É importante percebermos que a esfera social, a política e a econômica influenciaram as políticas educacionais durante todo o regime militar e essas influências não morreram com o tempo, continuam tendo sua força até os dias atuais.

\section{Referências}

ANTUNES, Ricardo. Os Sentidos do Trabalho: ensaio sobre a afirmação e a negação do trabalho. São Paulo: Boitempo Editorial, 2009.

ARANHA, Maria Lúcia de Arruda. História da educação. 2ed. São Paulo: Moderna, 1996.

BRASIL. Decreto-lei no 405 de 31 de dezembro de 1968. Disponível em: <http://www2.camara.leg.br/legin/fed/declei/1960-1969/decreto-lei-405-31dezembro-1968-376163-publicacaooriginal-1-pe.html>. Acesso em: 10 out. de 2017.

. Lei 5.540 de 28 de novembro de 1968. Disponível em: < http://www2.camara.leg.br/legin/fed/lei/1960-1969/lei-5540-28-novembro-1968359201-publicacaooriginal-1-pl.html>. Acesso em: Acesso em: 10 out. de 2017.

. Lei 5.692 de 11 de agosto de 1971. Disponível em:

<http://www.planalto.gov.br/ccivil_03/leis/L5692.htm>. Acesso em: 10 out. de 2017.

. Parecer 45 de 12 de janeiro de 1972. Disponível em: < siau.edunet.sp.gov.br/ltemLise/arquivos/notas/parcfe45_72.doc >. Acesso em: 10 out. de 2017.

. Parecer 76 de 23 de janeiro de 1975. Disponível em: < http://www.histedbr.fe.unicamp.br/navegando/fontes_escritas/7_Gov_Militar/parec er\%2076-

1975\%200\%20ensino\%20de\%202\%BA\%20grau\%20na\%20lei\%205.692-71.pdf >. Acesso em: 10 out. de 2017. 
. Lei 7.044 de 18 de outubro de 1982. Disponível em: < http://www.planalto.gov.br/ccivil_03/Leis/L7044.htm>. Acesso em: 10 out. de 2017.

BORGES, Nilson. A Doutrina da Segurança Nacional e os governos militares. In: DELGADO, Lucilia de Almeida Neves; FERREIRA, Jorge. (Org.). O tempo da ditadura: regime militar e movimentos sociais do século XX. Rio de Janeiro: Civilização Brasileira, 2007. p. 14-42.

BOURDIEU, Pierre. A escola conservadora: as desigualdades frente à escola e à cultura. In: . Escritos de educação. 12 ed. Rio de Janeiro: Vozes, 2011.

CUNHA, Luiz Antônio. O ensino profissional na irradiação do industrialismo. São Paulo: Editora UNESP, 2005.

FREITAG, Barbara. Escola, Estado e Sociedade. 7ed. São Paulo: Centauro Editora, 2005.

FRIGOTTO, Gaudêncio. A produtividade da escola improdutiva. 9ed. São Paulo: Cortez, 2010a.

Cortez, 2010b. . Educação e crise do capitalismo real. 6ed. São Paulo:

GAMBOA, Sílvio Sánchez. A globalização e os desafios da Educação no limiar do novo século. In: LOMBARDI, José Claudinei. (Org.). Globalização, Pósmodernidade e Educação: história, filosofia e temas transversais. Campinas: Associados, 2001.

GERMANO, José Willington. Estado militar e educação no Brasil (1964-1985). 5ed. São Paulo: Editora Contexto, 2011.

GHIRALDELLI, Paulo Jr. História da Educação. 2ed. São Paulo: Editora Cortez, 2001.

GRAMSCI, Antonio. Os intelectuais e a organização da cultura. Rio de Janeiro: Civilização Brasileira, 1979.

HABERT, Nadine. A década de 70: apogeu e crise da ditadura militar brasileira. 2ed. São Paulo: Ática, 1996.

HARVEY, David. A condição pós-moderna. São Paulo: Editora Loyola, 1993.

KUENZER, Acácia. Ensino médio e profissional: as políticas do Estado neoliberal. 2. ed. São Paulo: Cortez, 2000.

LIMA, Ricardo. Mercado de trabalho: o capital humano e a teoria da segmentação. Pesquisa e Planejamento Econômico, Rio de Janeiro, v. 1, n. 1, p.217-272, abr. 1980. Disponível em: 
<http://ppe.ipea.gov.br/index.php/ppe/article/viewFile/497/439\%3E.> Acesso em: 04 jun. 2016.

MASLOW, Abraham Harold. The Farther reaches of human nature. 3 ed. New York: Viking Press, 1973.

MOURA, Dante Henrique. Educação Básica e Educação Profissional e Tecnológica: Dualidade Histórica e perspectivas de Integração. HOLOS, Natal, v. 2, p. 4-30, 2007. Disponível em: $<$ http://www2.ifrn.edu.br/ojs/index.php/HOLOS/article/view/11/110>. Acesso em: 04 jun. 2017.

ROMANELLI, Otaíza de Oliveira. História da educação no Brasil: (1930/1973). 40 ed. Rio de Janeiro: Vozes, 2014.

SAVIANI, Demerval. Trabalho e educação: fundamentos ontológicos e históricos. Revista Brasileira de Educação, Rio de Janeiro, v. 1, n. 34, p. 152-180, jan/abr. 2007. Disponível em: < http://www.scielo.br/pdf/rbedu/v12n34/a12v1234.pdf>. Acesso em: 04 jun. 2018.

SCHULTZ, Theodore. O valor econômico da educação. Rio de Janeiro: Zahar Editores, 1967.

O capital humano: investimento em educação e pesquisa.

Trad. de Marco Aurélio de M. Matos. Rio de Janeiro: Zahar, 1973.

Recebido em: 18 de abril de 2018. Aprovado em: 09 de junho de 2018. Publicado em: 21 de novembro de 2018. 